\section{Inadäquate Schlafhygiene}

Helga Peter ${ }^{1}$ und Thomas Penzel ${ }^{2}$

${ }^{1}$ Marburg, Deutschland

${ }^{2}$ Interdisziplinäres Schlafmedizinisches Zentrum, Charité -

Universitätsmedizin Berlin, Berlin, Deutschland

\section{Englischer Begriff}

inadequate sleep hygiene

\section{Definition}

Inadäquater Umgang mit dem Schlaf. Siehe $\triangleright$,Schlafhygiene“. 